\title{
СОДЕРЖАНИЕ КОМПОНЕНТОВ ВНУТРЕННЕЙ КАРТИНЫ ДЕФЕКТА У ДОШКОЛЬНИКОВ С СЕНСОРНЫМИ НАРУШЕНИЯМИ
}

Адеева Т.Н., Севастьянова У.Ю. (Костромской государственный университет, Кострома, Россия)

adeeva.tanya@rambler.ru, ulyanakostroma@mail.ru

乙tinцmјшgर्üu uर्u.' 30.07.2019

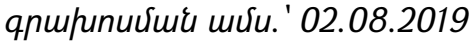

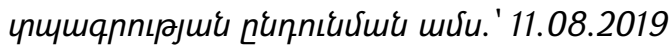

Внутренняя картина дефекта (ВКД) рассматривается как структура Яконцепции, как фрактор личностного развития. Особенности внутренней картины дефекта могут детерминировать вариант адаптации. Я-концепция дошкольников с дефицитарным развитием характеризуется преимущественно высоким уровнем самопринятия, высоким или средним уровнем самооценки. У детей с детским церебральным параличом не сформированы представления о себе как о друге вследствие малого количества социальных контактов. Содержание компонентов ВКД зависит от варианта нарушения и возраста. Компоненты ВКД у дошкольников содержательно мало наполнены, когнитивный компонент характеризуется стереотипностью. У дошкольников с нарушениями зрения отмечено доминирование эмоционального компонента в структуре ВКД. У дошкольников с детским церебральным параличом отмечено влияние структуры нарушения на физический, эмоциональный и мотивационный компоненты.

Ключевые слова: внутренняя картина дефекта, сенсорные нарушения, дошкольный возраст.

Проблема внутренней картины дефекта связаны с проблемой фрормирования самосознания, Я-концепции, актуальность которой не зависит от времени. Согласно исследованиям, образ «Я» в основе своей структуры имеет когнитивный, аффективный, поведенческий компоненты, влияющие на самооценку, самовосприятие человека. В старшем дошкольном возрасте развитие самосознания имеет определенную специфику. Ребенок начинает осознавать свои физические качества и возможности, умения. Определяет и оценивает нравственные нормы, собственные переживания. У детей начинает формироваться дифференцированная самооценка, способность мотивировать самооценку, появляется осознание себя во времени, личное сознание.

Ограниченные возможности здоровья являются специфическими условиями развития личности. Изменение сенсорных, фризических, психологических

3 Работа выполнена при финансовой поддержке Российского фонда фундаментальных исследований . (проект № 19-013-00768А) 
возможностей человека влияет на формирование отдельных компонентов и образа «Я» в целом. Вероятно, одним из факторов и механизмов формирования Яконцепции в ситуации дизонтогенеза будет становление внутренней картины дефекта (ВКД). Несмотря на использование термина, данный феномен недостаточно представлен в современной науке, и преимущественно исследование вопроса идет в русле изучения самосознания и Я-концепции. Проводится анализ специфики самовосприятия и самоотношения людей с дефицитарным развитием. В ряде работ выявлена зависимость самооценки лиц с нарушениями зрения от времени возникновения дефекта, варианта переживания дефекта, тяжести, формировании специфичных личностных черт нарушений $[3 ; 6]$. Некоторые исследователи заостряют снимание на неадекватности самооценки детей с нарушениями зрения, слуха. В зарубежных исследованиях выявлено, что дети с нарушениями зрения имеют заниженную самооценку по сравнению с типично развивающимися сверстниками, а также спад самооценки в период перехода от младшей школы к подростничеству. Подчеркивается зависимость специфики самооценки и ее реалистичности от социально-демографических и личностных факторов [3; 5; 6]. При нарушениях слуха у детей затруднено формирование представлений о качествах собственной личности, о специфике межличностных отношений. Самооценка детей зависит часто от отношения педагогов. Выявлено, что дошкольники с нарушениями слуха проходят те же стадии в развитии самосознания, но на 2-3 года позже [4]. В исследовании Е.Б. Акининой подчеркнута значимость формирования эмоционально-оценочного компонента самоотношения у лиц с нарушениями слуха. Согласно результатам работы, уверенность в себе является важнейшей чертой, коррелирующей с различными индивидуальнотипологическими параметрами, с самореализацией личности [1]. Возрастные особенности становления самосознания при детском церебральном параличе определены в исследовании Д.Г. Дьякова. Отмечена недостаточность развития рефлексии вследствие небольшого количества обратных социальных связей детей. В определении своих особенностей дети с ДЦП мало используют категории «внешность» и «социальные роли», меньше описывают свои способности, умения, навыки, характер [3]. Проанализированы основные варианты реакции личности на дефект, выявлены важные фракторы, определяющие тип реакции. В целом, в большинстве представленных работ основное внимание уделено эмоциональному компоненту самосознания, самооценке, варианту реакции на дефект.

В настоящем исследовании мы рассматриваем внутреннюю картину дефекта как составляющую самосознания, как сложное, интегративное образование; пониманием ВКД как комплекс ощущений, знаний, переживаний, мотивационных изменений, связанных с нарушением. Сенситивный компонент включает в себя совокупность ощущений, связанных с наличием дефректа. Физический компонент связан с характеристикой человеком собственной фризической активности, 
физических качеств. Когнитивный компонент представляет собой знания о причинах, проявлениях дефекта, ограничениях, связанных с его наличием. Эмоциональный компонент означает отношение личности к десекту. Мотивационный компонент, характеризует структуру мотивов личности, возможное её изменение в связи с наличием дефекта.

Цель исследования: изучение содержательной специфики компонентов внутренней картины дефекта у детей дошкольного возраста с дефицитарным типом дизонтогенеза (на примере нарушения фрункций ОДА, нарушения зрения, общее нарушение речи).

Выборку исследования составили дошкольники: 20 человек - дети с общим недоразвитием речи (ОНР), 12 человек - дети с нарушениями зрения (Н3); 6 человек - дети с нарушениями опорно-двигательного аппарата (НОДА). Средний возраст 6,5 лет. Исследование проводилось индивидуально.

Методики исследования: методика «Расскажи о себе» А.М. Щетининой (2000). Данная методика позволяет определить специфику компонентов Яконцепции: фризического (представление ребёнка о своих фризических качествах), деятельностного (представление об успешности овладения различными видами деятельности), социально-нравственного (представления о социальных нормах), а также выявить уровень и характер самооценки, степень осознания своего «Я». Методика позволяет получить косвенные данные о восприятии ребёнком отношения взрослого.

Беседа «Изучение внутренней картины дефекта» Т.Н. Адеевой (2018). Методика позволяет определить особенности компонентов ВКД. Ответы детей обработаны с использованием метода контент-анализа.

При изучении уровня и характера оценки, сорормированности образа "Я» по методике А.М. Щетининой получены следующие результаты. Максимальную выраженность и примерно одинаковое значение в трех группах имеют характеристики «Я-физическое», «Я - мальчик, девочка», «Я - в семье». Дети с дефицитарными нарушениями дают общую оценку собственным ффизическим параметрам («смешной», «красивый», «красивое платье, прическа, туфрли», «зеленые глаза, красивые наряды», «красивый свитер)». Выявленные особенности представлений ребенка о себе как о мальчике (девочке), сыне (дочке) также являются очень схожими во всех трех группах испытуемых («девочки всегда хорошо себя ведут, мальчики не очень», «мальчики защищают девочек», «девочки красивые», «не должны их обижать», «я хороший, добрый» и т.д.)

При сопоставлении данных методики «Расскажи о себе» по параметру «Я деятельностное» нами обнаружено значительное превалирование данного параметра у детей с H3 $(M=3,33)$, а также с небольшим снижением у детей с ОНР $(M=2,90)$ в сравнении с группой у детей с НОДА $(M=1,00)$. Эти данные подтверждаются такими высказываниями испытуемых с ОНР и Н3 в беседе, как я 
умею «ухаживать за овощами и фруктам, бегать лучше», «делать мостик, рисовать, лепить, выстригать, делать поделки», «мыть посуду, пол, белье руками стирать, помогать в огороде» и т.п. Мы склонны объяснять это наличием связи со структурой дефекта, а именно наличием двигательного нарушения у детей с НОДА. Дети практически не описывают себя в реальной деятельности и желании научиться чему-либо далее.

По параметру «Я - идеальное» несколько ниже средние значения в группе детей с нарушениями зрения $(M=1,78 ; \mathrm{SD}=0,44)$, по сравнению с детьми с ОНР $(M=2,10 ; S D=0,64)$ и нарушениями ОДА $(M=2,40 ; S D=0,55)$. «Я - идеальное» выявляет особенности осознания ребенком своих личностных качеств. В большинстве случаев у детей данной группы отмечается меньшее разнообразие характеристик себя, превалируют ответы: «я хороший; хочу стать умным, добрым». В группе детей с нарушениями речи, например, присутствуют такие ответы: «хочу стать героем, сильным, щедрым, богатым ...». Кроме того, дошкольники с нарушениями зрения затруднялись в фрормулировании собственных характеристик по разным параметрам беседы, периодически требовалась помощь взрослого. Это свидетельствует о снижении осознанности собственных качеств личности. Наши данные подтверждаются статистико-математической процедурой нахождения различий по критерии Манна-Уитни. Констатировано значимое снижение параметра "степень осознанности качеств" у группы детей НЗ в сравнении с группой детей с OHP $(U=41,0 ; p=0,02)$. Возможно, это связано и с повышенной тревожностью детей с нарушениями зрения по сравнению с детьми с нарушениями речи, с их осторожностью в формулировке ответов при оценке себя. (Отмечено статистически значимое различие по параметру «тревожность» по критерии Манна-Уитни $\mathrm{p}=0,04)$.

Другая часть беседы направлена на изучение представлений ребёнка о себе как друге. У детей с детским церебральным параличом не сфрормированы представления о себе как о друге вследствие малого количества социальных контактов (зафиксировано отсутствие ответов).

В целом, Я-концепция дошкольников с дефицитарным типом дизонтогенеза характеризуется преимущественно высоким уровнем самопринятия, высоким или средним уровнем самооценки, поскольку большую часть сторон образа "Я" осознает с позитивной позиции и лишь отдельные качества считает в себе плохими.

На следующем этапе изучены содержательные характеристики внутренней картины дефекта детей дошкольного возраста с дефицитарным типом дизонтогенеза. При анализе ответов детей, относящихся к сенситивному и фризическому компонентам выявлено, что дети с нарушениями зрения и нарушениями речи указывают на преобладание хорошего самочувствия, отсутствие неприятных ощущений. Страхи детей обусловлены, скорее, возрастом и не имеют специфики, связанной с дефектом. Физический компонент представлен более обширным содержанием у детей дошкольного возраста с $\mathrm{OHP}(\mathrm{M}=4,25 ; \mathrm{SD}=2,05)$ в сравнении 
с другими группами (в группе детей с нарушениями зрения $M=3,44 ; \mathrm{SD}=1,33$; в группе детей с нарушениями ОДА $M=2,80 ; \mathrm{SD}=1,64)$. Дети с ОНР чаще отмечают хорошее самочувствие, наличие у себя таких качеств как «сила, ловкость, скорость, быстрота», разнообразие пугающих ощущений, а именно: «когда смотрю страшилки», «когда ночью говорю», «пауков, паутины», «темноты, высоты», «боюсь одному быть в лесу» и т.д. Дошкольники с нарушениями речи и нарушениями зрения указывают на усталость при интеллектуальных нагрузках. В отличие от детей с нарушениями речи детей с Н3 практически не отмечают у себя физические качества «сила» и т.д. Мы склонны объяснять это наличием физического дискомфорта, обусловленного дефектом. В группе детей с НОДА физический компонент практически не наполнен, дети затрудняются давать характеристики фризическому состоянию. Характеристики часто противоречивы, ребёнок одновременно отмечает хорошее самочувствие и наличие боли при ежедневных делах и при физических нагрузках. В данной группе отсутствуют характеристики фризических качеств. Вероятно, это обусловлено спецификой дефекта, нарушениями двигательной сфреры и чувствительности.

Когнитивный компонент имеет примерно одинаковую количественную наполненность в группе детей с ОНР $(M=3,65 ; S D=2,03)$, нарушениями зрения $(M=4,44$; $\mathrm{SD}=1,67)$, нарушениями функций ОДА $(M=3,80 ; \mathrm{SD}=1,92)$. Однако содержание компонента отличается у детей с разными нарушениями. Признают наличие нарушения у себя $45 \%$ детей с нарушениями речи, $33 \%$ детей с нарушениями зрения и 80\% детей с нарушениями ОДА. Верят в возможность улучшения состояния почти $90 \%$ детей с нарушениями зрения и речи, а дошкольники с НОДА затруднились ответить на этот вопрос. Достаточно традиционно дети отвечают на вопросы о причинах нарушения: «смотрел долго телевизор», мерах профилактики и исправления нарушения: “смотреть меньше телевизор», «долго носить очки», «лечить глаза», «делать зарядку», «не сидеть в телефоне», «не отказываться ходить к врачу». У дошкольников присутствует представление об ограничениях, обусловленных состоянием, однако дети не связывают их с дефектом в своих ответах. Дети всех групп предпочитают подвижные игры. Однако реально играют в подвижные игры преимущественно дети с ОНР. При нарушениях речи у ребёнка достаточно ресурсов для использования этого вида деятельности. Дети с Н3 предпочитают играть в подвижные игры, но реально не делают этого из-за страха получения травм («не люблю с завязанными глазами, можно упасть», «можно разбиться»). А дети с НОДА не предпочитают подвижные игры и не играют в них в силу наличия двигательного дефекта. Таким образом нарушение может определять осознанность деятельности, которую выполняет ребёнок. Наконец, определяя трудные для себя занятия, дети с ОНР и Н3 дают более разнообразные ответы, в которых, превалируют трудности письма, чтения. Дошкольники с НОДА как наиболее трудные отмечают занятия фризкультурой. 
Анализируя характеристики мотивационного блока в структуре ВКД, можно констатировать одинаковую количественную наполняемость данного компонента у всех групп испытуемых (нравиться учиться, интересы, увлечения, желание для себя, желание для других). Однако содержательно можно увидеть явные, отличая в ответах детей, связанные со структурой нарушения. Интересы и увлечения у детей с ОНР различны: от занятия спортом до компьютерных игр («смотреть телевизор», «лепить из пластилина», «хожу с мамой часто в церковь, учу молитвы», «играть в телефон», «петь, танцевать», «играть», «компьютер», «гимнастика»), что характерно для детей статистической нормы данного возраста. Ограничений в выборе интересов у детей с ОНР нет. Тогда как дети с Н3 в основном предпочитают играть, заниматься продуктивной деятельностью и творчеством («рисовать, делать фригурки из глины», «пианино», «играть в дочки-матери, робота», «музыка»). На увлечения этой группы оказывает влияние дефект, детям с патологией зрения нельзя испытывать фризические нагрузки, а также нагрузки на зрительный анализатор. Дети с НОДА увлечены в основном компьютером («компьютер», «компьютер, мультики про трансформеров»), данные увлечения характерны для детей с вынужденной малой подвижностью. Примером ярко выраженной обусловленности влияния дефекта на мотивацию деятельности являются характеристики «хотел бы научиться» и «желание для себя». Дети с НОДА в основном хотят «ходить ножкам», «быстро бегать», «прыгать», тогда как другие дети двух групп хотели бы научиться «играть», «танцевать», «читать».

Стоит отметить, что эмоциональный компонент имеет большую выраженность у детей с нарушением зрения $(M=5,44 ; S D=1,01)$. Дети называют свои отличия и определяют то, что нравится в себе, преимущественно указывая на физические данные: «волосы, кожа», «лицо, руки», «веснушки». Затрудняются сформулировать свои личностные отличия, только один человек назвал: “характер». Дошкольники с нарушениями зрения указывают на отношение родителей: «родители хвалят, ругают, жалеют», но не формулируют причины родительского отношения. Дети демонстрируют выраженность эмоционального компонента, но в отличие от младших школьников нет специфичности отношения к нарушению. Сравнение результатов по критерию Манна-Уитни, выявило значимые различия по параметру эмоционального компонента ВКД между группами детей с ОНР и Н3 (U=28,5; $\mathrm{p}=0,02)$. Высокий уровень переживаний по поводу своих ощущений, по поводу впечатления производимого на окружающих характерны для детей с патологией зрения. Возможно, это обусловлено и спецификой социального окружения и отношения взрослых.

Эмоциональный компонент у детей с НОДА характеризуется меньшим количеством ответов $(M=2,60 ; \mathrm{SD}=1,14)$ по сравнению с двумя другими группами и меньшей наполненностью содержания. Дошкольники, в основном, характеризуют качества, которые им нравятся в себе, затрудняясь дать характеристику своим отличиям, редко характеризуют родительское отношение. 
Таким образом, содержание компонентов ВКД зависит от варианта нарушения и возраста. Компоненты ВКД у дошкольников содержательно мало наполнены, когнитивный компонент характеризуется стереотипностью. У дошкольников с нарушениями зрения отмечено доминирование эмоционального компонента в структуре ВКД. У дошкольников с детским церебральным параличом отмечено влияние структуры нарушения на физический, эмоциональный и мотивационный компоненты.

Полученные научные данные по изучаемой проблематике являются актуальными и необходимыми для оказания консультативной и коррекционной помощи детям с нарушениями в развитии.

В настоящее время завершён только первый этап исследования, планируется углубление и расширение материала по изучению компонентов ВКД у детей с разным типом дизоногенеза и выявление его особенностей в онтогенезе.

\section{Литература}

1. Акинина Е.Б. Самоотношение как ведущий психолого-акмеологический компонент в структуре личности глухих и слабослышащих студентов // Экономика образования, 2015, № 1, с. 103-107.

2. Дьяков Д.Г. Динамика самоидентификации как высшей психической функции у лиц с детским церебральным параличом в период подростничества // Здоровье. Личность. Общество: сборник научных трудов / сост. А.В.Алёшичева. Харьков: Финарт, 2014, с. 36-46.

3. Петренко В.Ф., Вайшвилайте В. Особенности категоризации собственного дефекта у людей с нарушением зрения // Вестник Московского университета. 1993. Серия 14: Психология, №3, с. 61-65.

4. Речицкая Е.Г., Хохлова О.С. Развитие самосознания детей с нарушением слуха дошкольного возраста // Непрерывное педагогическое образование в контексте инновационных проектов общественного развития. Сборник материалов VI Международной научно-практической конференции /Под общей редакцией С.Ю. Новоселовой. 2017, с. 1547-1552.

5. Papadopoulos K. The impact of individual characteristics in self-esteem and locus of control of young adults with visual impairments [Электронный ресурс] // Research in Developmental Disabilities, 2014, vol. 35, issue 3, pp. 671-675. URL:https://www.sciencedirect.com/science/article/abs/pii/S0891422213005520 (дата обращения: 16.04.2019) dx.doi.org/10.1016/j.ridd.2013.12.009.

6. Pinquart M., \& Pfeiffer J.P. Identity development in German adolescents with and without visual impairments [Электронный ресурс] // Journal of Visual Impairment \& Blindness, 2013, Vol. 107, №5, pp. 338-349. URL:https://journals.sagepub.com/doi/10.1177/0145482X1310700503 (дата обращения: 18.04.2019) dx.doi.org/10.1177/0145482X1310700503. 


\section{THE CONTENT OF THE COMPONENTS OF THE INTERNAL PATTERN OF DISORDER IN PRESCHOOL CHILDREN WITH SENSORY DISORDERS}

Adeeva T. N., Sevastyanova U. Yu. (Kostroma State University, Russia)

The internal pattern of disorder (IPD) is considered as the structure of the Selfconcept. Features of the internal pattern of the disorder can determine the adaptation option. Self-concept of preschoolers with deficit development is characterized mainly by a high level of self-acceptance. Children with cerebral palsy have no idea of themselves as a friend due to the small number of social contacts. The content of IPD components depends on the variant of dysontogenesis and age. In contrast to younger students, the components of IPD in preschool children with speech and visual impairment are filled with little content, the cognitive component is characterized by stereotype, and sensitive, emotional motivational components do not have specifics associated with the structure of the defect. In preschool children with visual impairment noted the dominance of the emotional component in the structure of IPD. The influence of the structure of the disorder on the physical, emotional and motivational components was noted in preschool children with cerebral palsy.

Keywords: internal pattern of disorder, sensory disorders, preschool age. 